University of Nebraska - Lincoln

DigitalCommons@University of Nebraska - Lincoln

USDA National Wildlife Research Center - Staff Publications
U.S. Department of Agriculture: Animal and Plant Health Inspection Service

2011

\title{
Domestic Calf Mortality And Producer Detection Rates In The Mexican Wolf Recovery Area: Implications For Livestock Management And Carnivore Compensation Schemes.
}

\author{
Stewart W. Breck \\ Bryan M. Kluever \\ University of Arizona \\ Michael Panasci \\ Texes Tech University, Lubbock \\ John Oakleaf \\ USFWS, Mexican Wolf Project \\ Terry Johnson \\ Arizona Game Fish Department
}

USDA/APHIS/WS National Wildlife Research Center, stewart.w.breck@aphis.usda.gov

See next page for additional authors

Follow this and additional works at: https://digitalcommons.unl.edu/icwdm_usdanwrc

Part of the Environmental Sciences Commons, and the Life Sciences Commons

Breck, Stewart W.; Kluever, Bryan M.; Panasci, Michael; Oakleaf, John; Johnson, Terry; Ballard, Warren B.; Howery, Larry; and Bergman, David L., "Domestic Calf Mortality And Producer Detection Rates In The Mexican Wolf Recovery Area: Implications For Livestock Management And Carnivore Compensation Schemes." (2011). USDA National Wildlife Research Center - Staff Publications. 1025.

https://digitalcommons.unl.edu/icwdm_usdanwrc/1025

This Article is brought to you for free and open access by the U.S. Department of Agriculture: Animal and Plant Health Inspection Service at DigitalCommons@University of Nebraska - Lincoln. It has been accepted for inclusion in USDA National Wildlife Research Center - Staff Publications by an authorized administrator of DigitalCommons@University of Nebraska - Lincoln. 


\section{Authors}

Stewart W. Breck, Bryan M. Kluever, Michael Panasci, John Oakleaf, Terry Johnson, Warren B. Ballard, Larry Howery, and David L. Bergman 


\title{
Domestic calf mortality and producer detection rates in the Mexican wolf recovery area: Implications for livestock management and carnivore compensation schemes
}

\author{
Stewart W. Breck ${ }^{\mathrm{a}, *}$, Bryan M. Kluever ${ }^{\mathrm{b}}$, Michael Panasci ${ }^{\mathrm{c}}$, John Oakleaf ${ }^{\mathrm{d}}$, Terry Johnson ${ }^{\mathrm{e}}$, Warren Ballard ${ }^{\mathrm{c}}$, \\ Larry Howery ${ }^{\mathrm{b}}$, David L. Bergman ${ }^{\mathrm{f}}$ \\ ${ }^{a}$ USDA-APHIS-WS-National Wildlife Research Center, 4101 LaPorte Ave., Fort Collins, CO 80521, USA \\ ${ }^{\mathrm{b}}$ School of Natural Resources, University of Arizona, Tucson, AZ 85721, USA \\ c Dept. of Natural Resources Management, Texas Tech University, Lubbock, TX 79409, USA \\ ${ }^{\mathrm{d}}$ USFWS, Mexican Wolf Project, 2105 Osuna NE, Albuquerque, NM 87113, USA \\ e Arizona GameFish Department, 5000 W. Carefree Highway, Phoenix, AZ 85086, USA \\ ${ }^{\mathrm{f}}$ USDA-APHIS-Wildlife Services, 8836 N 23rd Avenue, Suite 2, Phoenix, AZ 85021, USA
}

\section{A R T I C L E I N F O}

\section{Article history:}

Received 22 September 2010

Received in revised form 10 December 2010

Accepted 21 December 2010

Available online 13 January 2011

\section{Keywords:}

Compensation schemes

Livestock

Mortality

Predator

Producer detection rate

Survival

\begin{abstract}
A B S T R A C T
Conserving large carnivores throughout the world will often require that they share the landscape with livestock. Minimizing depredations and increasing tolerance by livestock producers will be critical for conservation efforts. To investigate factors influencing calf mortality and producer detection rates (i.e., number of livestock killed by predators, found by producers, and correctly classified as to cause of death), we monitored radio-tagged domestic calves at two sites in the Mexican wolf recovery area (East Eagle [EE] and Adobe Ranch [AR]). Study areas differed in grazing practices, density of predators (mountain lions, black bears, coyotes, and Mexican wolves), and amount of effort spent monitoring cattle. We radiotagged 618 calves over 3.5 years, and 312 calves over 2 years on the EE and AR, respectively. The overall proportion of radioed calves that died was higher on the EE (6.5\%) than on the AR (1.9\%). Predators (especially mountain lions) accounted for $85 \%$ of mortality on the EE and $0 \%$ on the AR. Calves selected by predators were on average 25 days younger than the surviving cohort. Our results indicate that year-round calving, especially in areas with high predator densities, are subject to higher losses primarily because calves are exposed to mortality agents for longer periods of time rather than having higher natural rates of mortality. We found a significant difference in producer detection rates between study sites, likely due to differences in the intensity of monitoring cattle between sites. On the EE, the producer detected $77.5 \%$ of mortalities and on the AR, the producer detected 33\% of mortalities. Our results support changing husbandry practices to limit calving to a seasonal endeavor and that performance payment may be a better compensation strategy than ex post compensation schemes.
\end{abstract}

Published by Elsevier Ltd.

\section{Introduction}

Conflict with humans is of growing importance for the conservation of large carnivores (Treves, 2009; Dar et al., 2009; Gusset et al., 2009). Historically, carnivore populations have been suppressed or exterminated, in large part because of their impacts on livestock (Bailey, 1907; Young and Goldman, 1944; McIntyre, 1995; Frank et al., 2005; Woodroffe et al., 2005). But with recent

\footnotetext{
* Corresponding author. Tel.: +1 970266 6092; fax: +1 9702666138.

E-mail addresses: Stewart.W.Breck@aphis.usda.gov (S.W. Breck),bmkluever@ yahoo.com (B.M. Kluever), michael.panasci@ttu.edu (M. Panasci), John_Oakleaf @fws.gov (J. Oakleaf), TJohnson@azgfd.gov (T. Johnson), Warren.Ballard@ttu.edu (W. Ballard), larry_howery@yahoo.com (L. Howery), David.L.Bergman@aphis.usda. gov (D.L. Bergman).
}

changes in public attitudes (Williams et al., 2002; Andersone and Ozolins, 2004; Ericsson et al., 2007), greater emphasis is being placed on maintaining and restoring large carnivore populations. Places where such carnivore populations are intact or have the potential for recovery also tend to be utilized for livestock production and conflict between carnivores and livestock producers inevitably becomes the focal point of opposition to conservation efforts (Blanco et al., 1992; Quigley and Crawshaw, 1992; Oli et al., 1994; Cozza et al., 1996; Odden et al., 2002; Fritts et al., 2003; Bangs et al., 2005). Better understanding of carnivore impacts on livestock and factors that influence this dynamic is important for reducing conflict and mitigating the economic impacts of large carnivores (Linnell et al., 1996; Sagor et al., 1997; Bangs et al., 2005).

Disease, accidents, malnutrition, exposure to weather, stress, and predation are all causes of mortality in livestock (Warren 
et al., 2001; National Agricultural Statistics Service, 2006) but the relative importance of each is often unknown especially in grazing systems in or near areas suitable for large carnivores. Often these areas are remote, difficult to access, and contain cattle with little human oversight. In grazing systems with multiple carnivore species, determination of the depredating predator can be confused because differences among kills of different predator species can be difficult to distinguish unless there is fresh evidence and the detector is skilled at performing field necropsies.

Compensation programs are a strategy being used to mitigate the economic impacts of carnivores on livestock (Muhly and Musiani, 2009; Bostedt and Grahn, 2008; Rondinini and Boitani, 2007). For programs that provide compensation after predation events occur (i.e., ex post compensation schemes), an important consideration is the producer detection rate, which we define as the number of livestock killed by predators, found by producers or government agents, and correctly classified as to cause of death. It is recognized that the number of depredations detected by producers is generally lower than the actual number occurring (Oakleaf et al., 2003; Swenson and Andren, 2005; Sommers et al., 2010). For example, findings from Oakleaf et al., 2003 found that as many as 8 cattle (Bos primigenius taurus) calves were killed by gray wolves (Canis lupus) for every one discovered by producers. This system may represent a worst case scenario because their work was conducted in heavily forested, remote, and rugged country. Regardless, caution is required when making inferences from this study to other systems as it is likely that both causes of mortality and detection rates vary due to a variety of factors that are not well understood but likely include terrain, vegetation type, grazing practices, the amount of time producers monitor their livestock, and the type and density of predator species.

In 1998, state and federal agencies began reintroducing Mexican wolves (Canis lupus baileyi) within the Blue Range Wolf Recovery Area (BRWRA) of Arizona and New Mexico, USA (Parsons, 1998). The impact that Mexican wolves have on livestock is a primary recovery concern (United States Fish and Wildlife Service, 2005) and justified conducting this research. More broadly, within the BRWRA a variety of predators prey upon domestic cattle (Cunningham et al., 1995; Reed et al., 2006), but no research has been conducted that explicitly investigated causes of livestock mortality or producer detection rates. Calves are generally the most vulnerable to predation (Palmeira et al., 2008; Rosas-Rosas et al., 2008; Sommers et al., 2010) and other mortality events and can be the most difficult to detect, therefore we focused our study on calf mortality in two study areas in or adjacent to the BRWRA. Our objectives were to (1) determine the impact of a suite of predators [mountain lions (Felis concolor), black bears (Ursus americanus), coyotes (Canis latrans) and Mexican wolves] on calves in the BRWRA, (2) describe how calf mortality and producer detection rates vary, (3) identify likely factors influencing mortality and detection rates, and (4) address how our results impact compensation schemes.

\section{Study area}

We monitored calves on two study sites, the East Eagle (EE) and the Adobe Ranch (AR) (Fig. 1). The EE is within the

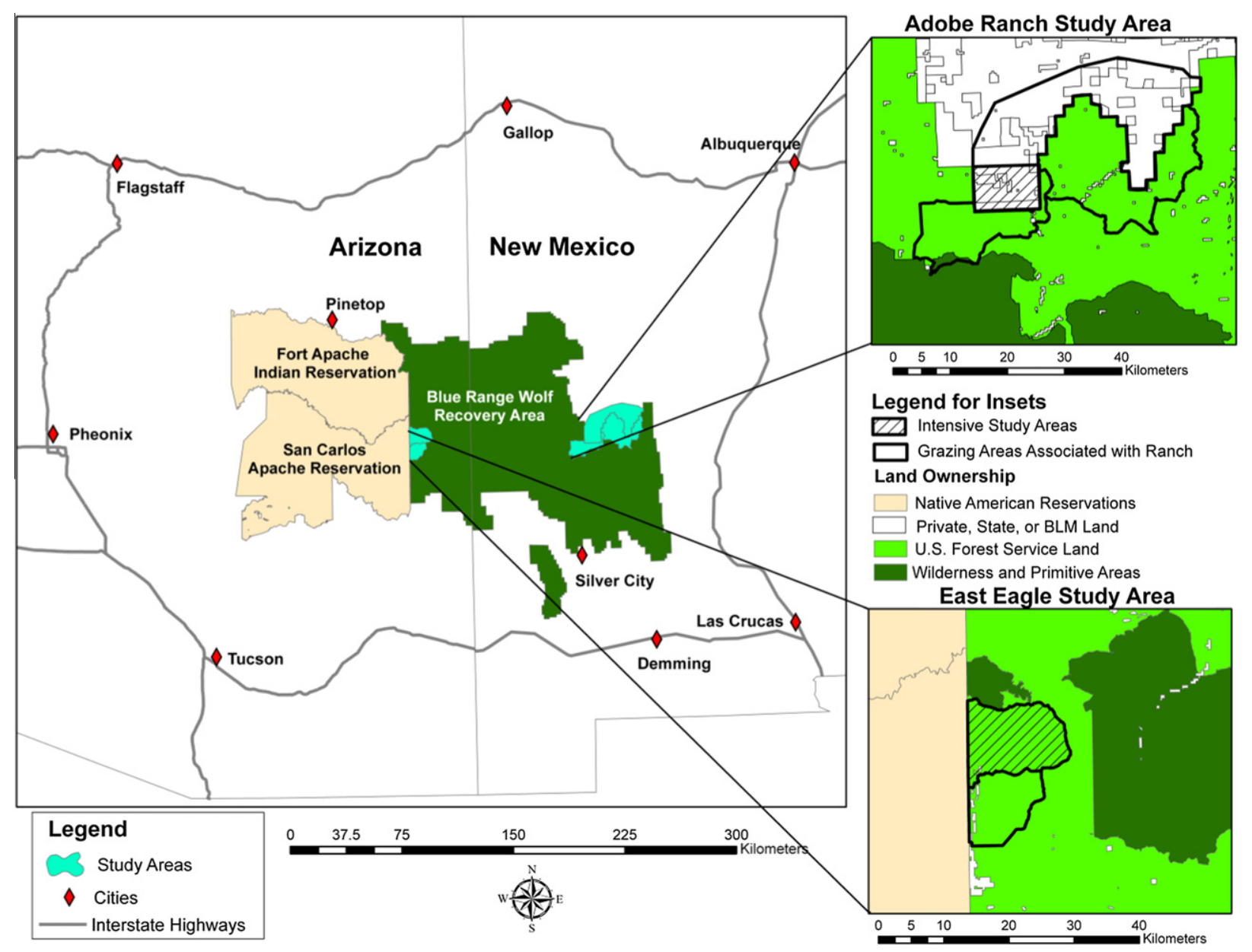

Fig. 1. Map of the Mexican wolf recovery area and calf mortality study areas (insets) in Arizona and New Mexico, respectively. 
Table 1

Description and comparison of two study areas (East Eagle and Adobe Ranch) where domestic calves were monitored in or adjacent to the Mexican wolf recovery area.

\begin{tabular}{|c|c|c|c|c|c|c|c|}
\hline $\begin{array}{l}\text { Study } \\
\text { site }\end{array}$ & $\begin{array}{l}\% \text { Forest } \\
\text { cover }\end{array}$ & $\begin{array}{l}\text { Relative density: lion and } \\
\text { black bear }\end{array}$ & $\begin{array}{l}\text { Relative density: } \\
\text { Mexican wolf }\end{array}$ & $\begin{array}{l}\text { Predator removal } \\
\text { occurred }\end{array}$ & $\begin{array}{l}\text { Grazing } \\
\text { regime }\end{array}$ & $\begin{array}{l}\text { Native ungulate } \\
\text { density }\end{array}$ & $\begin{array}{l}\text { Producer effort } \\
\text { monitoring cattle }\end{array}$ \\
\hline $\mathrm{EE}$ & $75 \%$ & High & Low & Yes & Year-round & Unknown & Higher \\
\hline AR & $25 \%$ & Low & Low & Yes & Seasonal & Unknown & Lower \\
\hline
\end{tabular}

Apache-Sitgreaves National Forest in eastern Arizona, encompasses approximately 30,000 ha, ranges in elevation from 1500 to $2600 \mathrm{~m}$, and contains mostly steep and rugged topography, ranging from thickly timbered areas to open meadows. Woody vegetation on the EE included ponderosa pine (Pinus ponderosa), pinyon pine (Pinus edulis), alligator juniper (Juniperus deppeana), oaks (Quercus spp.), and honey mesquite (Prosopis glandulosa); approximately $75 \%$ of the study area contained woody vegetation (visual estimate). The producer grazed from 150 to 300 cow-calf pairs and between 50 and 100 yearlings per year during 3.5 years of study on the EE (Table 1). The AR is within and adjacent to the Gila National Forest of west-central New Mexico and encompasses approximately 116,600 ha. It is comprised of roughly $1 / 3$ private, $1 / 3$ federal, and $1 / 3$ state lands and ranges in elevation from 2400 to $3300 \mathrm{~m}$. Terrain is mostly flat open grassland and rolling hills cut by moderately steep canyons and rocky washes with some heavily forested mountainous terrain. Woody vegetation on the AR included ponderosa pine, juniper, piñon pine, and oaks and approximately $25 \%$ of the study site contained woody vegetation (visual estimate). The producer grazed approximately 2000 cowcalf pairs and several thousand yearlings per year during the 1.5 years of study on the AR (Table 1 ). Because we could only tag a percentage of calves on the AR, we focused our tagging effort in pastures that the rancher believed had the most threat from predators. Generally these pastures were closer to heavily forested areas and were areas that the rancher indicated had a higher likelihood of having wolf activity. Thus our study occurred in six pastures in areas comprised mostly of open grassland and rolling hills with some areas with steep topography and forested terrain.

Native ungulates on both study areas included Rocky Mountain elk (Cervus elaphus) and mule deer (Odocoileus hemionus), and other prey species included collared peccary (Pecari tajacu), black-tailed jackrabbits (Lepus californicus), cottontail rabbits (Sylvilagus spp.), and many species of rodents. In addition, Coues white-tailed deer (Odocoileus virginianus couesi) were present in low numbers on the EE, but not present on the AR. There was no data available to compare prey biomass density between study sites, but anecdotally there did not appear to be sizeable differences between sites. The EE was believed to contain relatively high densities of mountain lions and black bears (Arizona Game and Fish Department, unpublished data), with the opposite pattern on the AR (i.e., relatively low densities of lions and bears) (Table 1). Both sites had unknown but what we deemed comparable densities of coyotes. Prior to our study, calf mortality on the EE due to mountain lion and black bear predation was believed to be an important source of mortality, annually accounting for approximately 10-30 calves killed (producer, personal communication).

Mexican wolves were present and actively managed in both study areas. On the EE the number of wolves potentially in the study area (i.e., home ranges of wolves encompassed study area) varied between 9 and 15 individuals in 2-4 packs from 2003 to 2006 (unpublished data). On the EE a wolf pack was removed due to boundary violations [e.g., outside of the BRWRA on the San Carlos Apache Reservation (Fig. 1)] prior to the start of the study in June 2003. On the AR the number of wolves potentially in the study area (i.e., home ranges of wolves encompassed study area) varied between 0 and 11 individuals in 1-3 packs from
2006 to 2007. On the AR, a repeated pattern of depredations and removal of wolves occurred through time. Removal of wolves that had at least one depredation on the AR include; two adults in 2001; two adults in 2002; two adults and two sub-adults in 2006; and five adults, two sub-adults, and three pups in 2007 (Arizona Game and Fish Department et al., 2003a,b, 2007, 2008).

\section{Methods}

We used radiotransmitters with a 2-h mortality switch (Advanced Telemetry Systems, Isanti, Minnesota, USA) to monitor calves during June 2003-October 2007. Our goal was to attach radiotags to calves within 2 weeks of birth. On the EE and AR we radiotagged approximately $75 \%$ and $50 \%$ of calves, respectively within 2 weeks of birth; the remaining calves were radiotagged between 1 and 2 months of age. On the EE, calves were born year-round with approximately 70\% born in 6 months between March and August. We radiotagged 141, 140,134, and 203 calves (annually representing 93-96\% of the calf crop) from 2003 to 2006, respectively, concentrating most of our effort during spring and summer months. We also tagged calves in fall to allow monitoring through the winter. On the AR most calves (95\%) were born in a 4 month period from February to May and were off the range by October/November. We radiotagged 100 and 212 calves during 2006 and 2007, respectively, which represented a small percentage (approximately $5-10 \%$ ) of the annual calf crop. All work was approved by the National Wildlife Research Center's Institutional Animal Care and Use Committee QA-1251.

\subsection{Monitoring cattle-telemetry crew}

On the $\mathrm{EE}$, we monitored radio signals continuously for the duration of the study with monitoring intensity varying primarily by season. Daily monitoring occurred from mid-May through October in 2003, 2005, and 2006 and involved personnel finding high spots and using three element antennas and standard telemetry receiving equipment to check for mortality signals. We checked signals 1-2 times/day and supplemented daily telemetry monitoring by monitoring cattle via visual observation. We performed weekly monitoring during the rest of the year (i.e., October-mid-May) in 2003, 2005, and 2006, and during the entire year in 2004. Weekly monitoring involved checking signals once a week, usually from higher points outside the grazing allotments. We did not use visual observations to supplement the telemetry effort during these time periods. On the AR we monitored cattle on a daily basis from mid-April through September during 2006 and 2007, similar to monitoring protocols on the EE. We did not monitor any calves on the AR through winter periods (November-February) because calves were taken to market in October and no calves were born in the fall or winter.

Any time a mortality signal was detected the transmitter was located as quickly as possible, typically within 3-12 h from the daily monitoring period. During periods of weekly monitoring, transmitters took longer to find, typically 2-4 days. We also documented mortalities of calves that were not radiotagged but were found using other detection methods [e.g., opportunistically 
or following scavengers like turkey vultures (Cathartes aura) and common ravens (Corvus corax)]. For any carcass discovered, we called a US Department of Agriculture-Wildlife Services (WS) Wildlife Specialist to investigate the carcass for cause of death (Roy and Dorrance, 1976; Fritts, 1982). We classified calves that died of causes other than predation as "non-predator" and this included calves that died of disease, accidents, malnutrition, or other causes. The telemetry crew did not share information with the producer for at least 2 weeks after a mortality to ensure that detection rates and producer management decisions were not influenced by results from the telemetry monitoring.

\subsection{Monitoring cattle-producer}

On the EE the producer monitored cattle at least 1-2 times per week and often on a daily basis from March to October. This involved ranch hands riding pastures within the allotments and searching for newly born calves, monitoring animal health, and moving livestock among pastures within the allotment. Daily activities and observations were recorded in a field notebook and included information on ear tags attached to newly born calves (both radiotelemetry and identification tags), calf color, gender, birth date, and mothers of the calves. The producer often used 6-12 trained dogs (Canis familiaris) for help locating dead and new-born calves, locating livestock in dense vegetation, and following predator scent when depredations were found. Other methods for locating dead calves included monitoring scavenger activity (e.g., turkey vultures) and observing the condition and behavior of lactating females. Monitoring during winter months (NovemberFebruary) was sporadic and characterized as occasional visits to pastures depending on severity of weather. Monitoring on the AR by the producer was at a much lower intensity than on the EE, primarily because the area with calves and the total number of calves was nearly an order of magnitude larger. Generally, monitoring of calves occurred sporadically, as two ranch hands were responsible for cattle in the six pastures with the transmittered calves in addition to other pastures without radiotagged cattle. Much of the monitoring occurred while dispersing cattle from watering areas and while performing other ranching-related duties. As on the $\mathrm{EE}$, ranch hands would use the presence of vultures or other scavengers to alert them to possible dead livestock. At least once a week, a ranch hand would check on cattle in most pastures. This was primarily performed on horseback and generally did not include the use of trained dogs.

A WS Wildlife Specialist was called to confirm the cause of mortality when producers found calf mortalities and suspected predation as a likely cause. This specialist operated independently of the telemetry monitoring crew without knowledge of our findings. On the EE, the producer practiced normal efforts to prevent depredation, including non-lethal and lethal management of bears, lions, and coyotes following appropriate Arizona Revised Statutes and Arizona Game and Fish Commission Rules. Predator control on AR was limited to WS personnel and opportunistic shooting of coyotes by local ranchers and ranch hands following appropriate New Mexico laws. On the EE, cattle roundups occurred every fall (October-November) and spring (late May/early June) and on the $A R$, roundups occurred in the fall and summer (June-July). Cows and calves were culled from the herd at the producer's discretion. Roundups allowed us to assess the functioning of radiotags and confirm survival of calves that dropped radiotags.

\subsection{Statistical analyses}

We calculated the proportion of radiotagged calves that died by summing all unique mortalities found by both the telemetry crew and the producer and dividing the sum by the total number of calves. We used a Chi Square (SAS Institute, 2003) to test for a difference in the proportion of calves that died between the EE and AR. We further partitioned the mortality events by different mortality factors (i.e., different predator species, non-predation, and unknown) and present this as a descriptive summary for each study area.

We performed a survival analysis to determine whether rates of calf mortality differed between study areas and among years within study areas (i.e., EE-2003, EE-2005, EE-2006, AR-2006, and AR2007). We included all mortality events of radiotagged calves in the analysis and used the known fates option in program MARK (White and Burnham, 1999) to analyze data. We limited the analysis period to 22 weeks (late May through September) because our most consistent monitoring effort occurred during this time period and generally our largest number calves with functioning radiotransmitters occurred during this period. Individuals were right censured if their tag was known to have failed, fallen off, or assumed to have failed due to loss of signal. We excluded data from EE during 2004 because the daily monitoring effort was not equivalent to other years. For both analyses, we collapsed the daily monitoring effort into weekly periods and classified each individual as alive or dead for each week based on radiotelemetry and visual observation recorded by the telemetry crew. Based on knowledge of the system and mortality events, we hypothesized that survival of calves would be generally lower on the EE than the AR, which is represented as Model 7 in Table 1 . We challenged this model to a variety of other models representing differences in survival between sites and years in an exploratory analysis (Table 1). We used the small sample correction of AIC to determine model rankings and used the top model to report survival probabilities for each site-year for the 22 week period (Burnham and Anderson, 2002).

On both ranches there was a range of different-aged calves available to predators. We assumed that age of calf reflected the size of a calf and tested whether predators selectively killed younger/smaller calves. We compared the age of calves killed with the mean age of all other calves at the time of the predation event. We only used data from radiotagged calves killed by predators. We used a two sample $t$-test to test for differences between the mean age of calves killed and the mean age of calves available (SAS Institute, 2003) and tested whether calves killed would be younger than available calves.

Both the telemetry crew and livestock operators had the opportunity to independently find and classify all mortalities. For every mortality event of radiotagged calves, we recorded whether each monitoring group discovered the mortality and what they determined was the cause of death (i.e., unknown, still born, non-predator, mountain lion, wolf, black bear, or coyote). We calculated the probability of each group finding mortalities by taking the number found by each group and dividing by the total mortalities found by both groups. For mortalities that both groups found and independently determined cause of death, we calculated the percentage of events where both groups agreed upon the cause of death. Because of small sample sizes we used a Fisher's exact test to test for differences in detection rate between the EE and AR (SAS Institute, 2003).

\section{Results}

We radiotagged and monitored 618 calves in 3.5 years on the EE and 312 calves in 1.5 years on the AR. The proportion of calves that died was significantly higher (ChiSquare $=9.13, d f=1, p=0.003$ ) on the $\mathrm{EE}(6.5 \%)$ than on the AR (1.9\%) with predators, especially mountain lions, being the primary cause of mortality on the EE but not on the AR (Table 2). We found little support for the idea that calf survival rates differed between EE and AR for the 22 week 
Table 2

Fates of radio-tagged domestic calves on two study areas (East Eagle and Adobe Ranch) in or adjacent to the Mexican wolf recovery area.

\begin{tabular}{|c|c|c|c|c|c|c|c|c|}
\hline \multirow[t]{2}{*}{ Study site } & \multirow{2}{*}{$\begin{array}{l}\text { Number of } \\
\text { calves radioed }\end{array}$} & \multirow{2}{*}{$\begin{array}{l}\text { Number and (\%) of } \\
\text { calves that died }\end{array}$} & \multicolumn{6}{|c|}{ Cause of death } \\
\hline & & & Lion & Wolf & Black bear & Coyote & Non-predation & Unknown \\
\hline $\mathrm{EE}$ & 618 & $40(6.5 \%)$ & 27 (67.5\%) & $3(7.5 \%)$ & $3(7.5 \%)$ & $1(2.5 \%)$ & $4(10 \%)$ & $2(5.0 \%)$ \\
\hline $\mathrm{AR}$ & 312 & $6(1.9 \%)$ & $0(0.0 \%)$ & $0(0.0 \%)$ & $0(0.0 \%)$ & $0(0.0 \%)$ & $4(66.7 \%)$ & $2(33.3 \%)$ \\
\hline
\end{tabular}

Table 3

The 12 candidate models testing for differences in domestic calf survival on the East Eagle and Adobe Ranch using model selection based on Akaike Information Criterion (AIC). AICc Weight is an estimate of support for each model, and Num. Par. is the number of parameters in a model. Variables in models are: site/year, for example EE03 represents the East Eagle study site in 2003 and AR06 represents the Adobe Ranch in 2006 . In the following models "v" indicates a differences in survival rate between variables and " $=$ " indicates calf survival is equivalent.

\begin{tabular}{|c|c|c|c|c|c|}
\hline & Model & AICc & AICc weight & Num. Par. & Deviance \\
\hline (1) & S: $($ EE03 $=$ EE06 $=$ AR06 v EE05 = AR07 $)$ & 349.16 & 0.214 & 2 & 73.74 \\
\hline (2) & S: $($ EE03 = EE05 $=$ EE06 $=$ AR06 $=$ AR07 $)$ & 350.03 & 0.138 & 1 & 76.62 \\
\hline (3) & S: $($ EE03 $=$ EE05 $=$ EE06 $=$ AR06 $v$ AR07 $)$ & 350.16 & 0.129 & 2 & 74.74 \\
\hline (4) & S: $($ EE05 $=$ EE06 $=$ AR07 v EE03 = AR06 $)$ & 350.23 & 0.125 & 2 & 74.82 \\
\hline (5) & S: $($ EE03 v EE05 = EE06 = AR06 = AR07 $)$ & 350.63 & 0.102 & 2 & 75.22 \\
\hline (6) & S: $($ EE03 v EE05 = AR07 v EE06 = AR06 $)$ & 350.82 & 0.093 & 3 & 73.40 \\
\hline (7) & S: $($ EE03 $=$ EE05 $=$ EE06 v AR06 $=$ AR07 $)$ & 351.49 & 0.067 & 2 & 76.07 \\
\hline (8) & S: $($ EE03 v EE05 $=$ EE06 v AR06 = AR07 $)$ & 352.53 & 0.040 & 3 & 75.11 \\
\hline (9) & S: $($ EE03 v EE06 v AR06 v EE05 = AR07) & 352.79 & 0.035 & 4 & 73.37 \\
\hline (10) & S: $($ EE03 = EE05 v EE06 v AR06 = AR07 $)$ & 353.49 & 0.025 & 3 & 76.07 \\
\hline (11) & S: $($ EE03 v EE05 v EE06 v AR06 = AR07) & 353.98 & 0.019 & 4 & 74.56 \\
\hline (12) & S: (EE03 v EE05 v EE06 v AR06 v AR07) & 354.62 & 0.014 & 5 & 73.19 \\
\hline
\end{tabular}

period late May through September (model 7, weight $=0.07$, Table 3). The top model had nearly twice as much weight $(0.21)$ as any other model and indicated that calf survival $(S \pm S E)$ was equivalent and highest $(0.973 \pm 0.012)$ on the EE-2005 and AR2007 and slightly lower and equivalent $(0.941 \pm 0.013)$ for EE2003, EE-2006, and AR-2006 (Table 2). We used 19 predator kills from 2003, 2005, and 2006 to test whether predators selected for younger/smaller animals. Age $(\bar{x} \pm S E)$ of predator killed calves was 47.6 days \pm 8.5 (range $6-142$ days) and significantly younger $(t=-2.010, d f=36, p$-value $=0.026)$ than the average age of available calves $72.4 \pm 8.9$ (range $21-145$ days).

Producer detection rates were over twice as high on the EE (31 out of $40: 77.5 \%$ ) than on the AR ( 2 out of $6: 33.3 \%$ ) (Fisher's exact test: $p=0.045)$. Of the 34 predator-caused mortalities on the EE, the producer detected 27 (79.4\%) and the telemetry crew detected 19 (55.9\%). Fourteen mortalities were found and verified by both groups; 13 (92.9\%) of these mortalities were independently confirmed as the same cause of death. The one mortality that was classified differently between monitoring groups was confirmed as a mountain lion kill by the producer and a black bear kill by the telemetry crew. The telemetry crew and producer both found and identified three mortalities as wolf kills (producer detection rate $=100 \%$ ).

\section{Discussion}

The proportion of livestock that die in the field is a function of both the rate of mortality and the amount of time calves are exposed to mortality agents. We found that the proportion of radiotagged calves that died was over three times higher on the EE (6.5\%) than the AR (1.9\%), indicating that on the EE either rates of mortality were higher or calves were exposed to mortality agents for longer periods, or both. Results of the survival analysis indicated that rates of mortality were not significantly different between the EE and AR and support the notion that the difference in mortality between the EE and AR was primarily due to the duration of exposure to mortality agents on the EE and not necessarily higher rates of mortality.
Most mortality on the EE was due to predation, with mountain lions accounting for $79 \%$ of all predation (27 kills) and Mexican wolves, black bears, and coyotes accounting for the remaining predation events (seven kills total, $21 \%$ of predation events). These results contrasted with results from the AR where we did not document any predation mortality of radioed calves and other studies where predation played a less important role (e.g., Mazzolli et al., 2002; Oakleaf et al., 2003). However, it is important to note that on the AR some predation by wolves was documented on uncollared calves outside our study pastures (Arizona Game and Fish Department et al., 2007, 2008). These events contributed to the removal of 14 wolves and may have decreased the probability of our collared calves being killed by wolves. Nonetheless strong differences in rates of predation were apparent between the EE and AR.

In general, differences in predator impacts between sites can reflect the interplay between relative densities of different predator species (Sagor et al., 1997; Stahl et al., 2001), difference in probabilities of predator species and individuals killing livestock (Stahl et al., 2001; Collinge, 2008), and vulnerability of livestock to predation. The EE had higher densities of mountain lions and black bears and had calves born year-round (i.e., increasing the vulnerability of their livestock); these differences likely account for most of the difference between sites. It is possible that on the EE an individual predator developed a strong predilection for killing livestock (Stahl et al., 2001) and as a result caused higher rates of predation. However, we believe this is highly unlikely because of the continual removal of predators that occurred on the EE making it unlikely that an individual animal would have the ability to develop a search image for calves. Our results indicate that narrowing the birth pulse of calves could be an important mechanism for reducing overall losses of livestock.

We documented strong age-biased depredation patterns on the EE where calves killed by predators were 25 days younger than the average age of available calves indicating there was a selection pressure by predators to kill younger/smaller calves; similar findings were reported by Yom-Tov et al. (1995), Stahl et al. (2001), Oakleaf et al. (2003), and Michalski et al. (2006). This selection pressure has potential ramifications for producers in that decreasing the temporal period when calves are born could help reduce 
predation on calves. Two lines of reasoning follow. First, as calves grow they become less vulnerable to predation and at some point get large enough to generally escape predators. This argument has never been tested and may have some merit for smaller predators like coyotes, but we documented lions killing 300-lb calves on the $\mathrm{EE}$ and it is well known that both lions and wolves commonly prey upon large adult ungulates. Therefore, it is questionable whether a narrow temporal window of calving would significantly reduce predation. However, there may be merit to the idea that predators more easily learn to kill a prey type when young are available and by having a perpetual supply of young animals in the field could impact the learning process of predators. Second, predators killing smaller prey will theoretically need to increase their kill rate to match caloric requirements. Thus it is possible in areas with year-around breeding/calving that kill rates of predators will be higher than in areas without year-around breeding. To our knowledge this idea has not been addressed in relation to grazing livestock but may hold some merit.

Documenting and understanding patterns of large carnivore predation on livestock has become a priority in many regions throughout the world (Graham et al., 2005). Many studies rely on reports from producers or trained biologist but without the aid of radio-telemetry (e.g., Michalski et al., 2006; Kolowski and Holekamp, 2006; Holmern et al., 2007; Schiess-Meier et al., 2007; Namgail et al., 2007; Palmeira et al., 2008; Rosas-Rosas et al., 2008). We found that producer detection rates can be highly variable and speculate that variability between sites is primarily driven by the amount of effort spent searching for livestock. On the EE we estimated that $77.5 \%$ of calf mortalities, $79.4 \%$ of predator-killed mortalities, and $100 \%$ of calves killed by wolves were found and correctly classified by the producer. Our results contrast sharply with results from the AR (33\% detection rate) and with Oakleaf et al. (2003), which estimated a $12.5 \%$ producer detection rate of calves killed by wolves. Considering the difficult terrain and the year-around grazing practices on the EE, our results are surprising. Several factors contributed to the high detection rates, but we believe the primary explanation was the effort expended by the producer to monitor cattle. From March to November, the producer monitored the livestock on nearly a daily basis, performing livestock husbandry tasks such as tagging newborn calves, learning mother-calf relationships, and paying close attention to each individual cow and calf. Of particular importance was the help from a highly experienced and dedicated ranch hand and the use of dogs for finding cattle.

Pack species will consume a carcass more quickly than a solitary species. Thus it is reasonable to hypothesize that detection rates for wolf kills will be lower because the carcass would be consumed faster and therefore more difficult to find. However, we did not find evidence to support this hypothesis. In fact, our results suggest the opposite was true in that the producer found $100 \%$ of wolf kills and $78 \%$ of lion kills. Sample sizes in our study were small, thus we caution against over interpretation of our findings, however finding from Oakleaf et al. (2003) also do not support this hypothesis as they found detection rates were lower for non-predator mortalities than for predator-caused mortalities.

On the EE, the producer found and classified eight mortalities that the telemetry crew did not find or investigate. We used these mortalities in the analysis and it is possible that our results are biased because of misclassification errors on the part of the producer. We do not believe this is the case as the producer and ranch hands had extensive experience with assessing calf mortalities and on cases when predation was a possibility, personnel from WS were called into verify kills. Furthermore, of 14 mortalities that were investigated by both producer and telemetry crew, 13 $(92.9 \%)$ were classified the same indicating producers were accurate in their assessment of mortality. The one discrepancy was a predator kill that the telemetry crew classified as black bear and the producer classified as lion.

\section{Conclusions}

Understanding the impact of predators on livestock can aid in developing management strategies that minimize carnivore-livestock conflict. Our study supports the idea that in areas with high predation risk, limiting calving to a seasonal endeavor may provide significant reduction in calf mortality. This would require changing livestock husbandry practices so that birthing of calves occurred as a pulse instead of continuously throughout the year. Alternatively, if knowledge of predator use of an area (i.e., wolf rendezvous sites) were available then using diversionary feeding of livestock, providing alternative water sources, or providing alternative predator-free pastures to maintain spatial separation of predators and livestock might provide reduced rates of predator-caused mortality. Our study also indicated predators selected for younger/smaller calves and it is possible that decreasing the temporal extent of the birth pulse could help reduce predation impacts either by limiting the time period that vulnerable calves are on pasture or by influencing the energetics of predators.

We demonstrated that producer detection rate can be highly variable between ranches, which has two important consequences. First, studies that rely on reports from producers instead of collecting data by monitoring predators or prey should account for producer effort (e.g., Palmeira et al., 2008) when comparing across sites. Second, compensation programs that rely on verifying predation events to receive compensation (i.e., ex post compensation schemes) may not be fair unless producer effort is also quantified (e.g., Sommers et al., 2010). Thus a better scheme may be a performance-payment scheme (Zabel and Holm-Müller, 2008) where payment is based on conservation outcomes (e.g., carnivore offspring) and the compensation is based on damage that animals are expected to cause. There is no need for producers to find kills, have an expert verify kills, and estimate detection rates. Performance-payment schemes also present challenges to implement (Zabel and Holm-Müller, 2008) but given the great discrepancy in detection rates that we documented and is likely inherent across producers, a performance-payment system likely offers a better option.

\section{Acknowledgements}

Funding for this research was provided primarily by the Arizona Game and Fish Department and New Mexico Game and Fish Department, with additional funds from USDA-APHIS-WS-Arizona Program, USDA-WS-National Wildlife Research Center, US Forest Service, California Wolf Center, and T\&E Inc. We thank the following for their dedication in the field: A. Bristol, M. Robin, L.G. Fornara, J. Reed, S. Smith, J. Dolphin, A. Block, J. Timmer, and numerous volunteers. Special thanks to J.B. Miller and S. Sterling from USDAAPHIS-WS for their assistance with field necropsies and support with monitoring calves throughout the study. T. Veenendaal, C. Carrillo, and P. Valentino provided essential logistical support. We thank the producers and their employees for their patience and cooperation throughout this study and their willingness to participate in this challenging endeavor. The views expressed in this article are those of the authors, and do not necessarily reflect the view of the agency.

\section{References}

Andersone, Z., Ozolins, J., 2004. Public perception of large carnivores in Latvia. Ursus 15, 181-187. 
Arizona Game and Fish Department [AGFD], New Mexico Department of Game and Fish, US Department of Agriculture - Animal and Plant Health Inspection Service - Wildlife Services, US. Fish and Wildlife Service, and White Mountain Apache Tribe, 2003a. Mexican wolf Blue Range Reintroduction Project: Interagency Field Team Report. <http://www.azgfd.gov/w_c/wolf/ reports.shtml> (reporting period January 1-December 31, 2001).

Arizona Game and Fish Department [AGFD], New Mexico Department of Game and Fish, US Department of Agriculture - Animal and Plant Health Inspection Service - Wildlife Services, US. Fish and Wildlife Service, and White Mountain Apache Tribe, 2003b. Mexican Wolf Blue Range Reintroduction Project: Interagency Field Team Report. <http://www.azgfd.gov/w_c/wolf/ reports.shtml> (reporting period January 1-December 31, 2002).

Arizona Game and Fish Department [AGFD], New Mexico Department of Game and Fish, US Department of Agriculture - Animal and Plant Health Inspection Service - Wildlife Services, US. Fish and Wildlife Service, and White Mountain Apache Tribe, 2007. Mexican Wolf Blue Range Reintroduction Project: Interagency Field Team Report. <http://www.azgfd.gov/w_c/wolf/ reports.shtml> (reporting period January 1-December 31, 2006).

Arizona Game and Fish Department [AGFD], New Mexico Department of Game and Fish, US Department of Agriculture - Animal and Plant Health Inspection Service - Wildlife Services, US. Fish and Wildlife Service, and White Mountain Apache Tribe, 2008. Mexican Wolf Blue Range Reintroduction Project: Interagency Field Team Report. <http://www.azgfd.gov/w_c/wolf/ reports.shtml> (reporting period January 1-December 31, 2007).

Bailey, V., 1907. Wolves in Relation to Stock, Game, and the National Forest Reserves. Forest Service Bulletin 72 US Department of Agriculture, 31p.

Bangs, E.E., Fontaine, J.A., Jimenez, M.D., Meier, T.J., Bradley, E.H., Niemeyer, C.C., Smith, D.W., Mack, C.M., Asher, V., Oakleaf, J.K., 2005. Managing wolf-human conflict in the northwestern United States. In: Woodroffe, R., Thirgood, S. Rabinowitz, A. (Eds.), People and Wildlife: Conflict or Coexistence? Cambridge University Press, London, pp. 340-356.

Blanco, J.C., Reig, S., Delacuesta, L., 1992. Distribution, status and conservation problems of the wolf Canis lupus in Spain. Biological Conservation 60, 73-80.

Bostedt, G., Grahn, P., 2008. Estimating cost functions for the four large carnivores in Sweden. Ecological Economics 68, 517-524.

Burnham, K.P., Anderson, D.R., 2002. Model Selection and Multi-Model Inference. A Practical Information-Theoretic Approach, second ed. Springer-Verlag, New York.

Collinge, M., 2008. Relative risks of predation on livestock posed by individual wolves, black bears, mountain lions, and coyotes in Idaho. In: Timm, R.M. Madon, M.B. (Eds.), Proceedings of the 23rd Vertebrate Pest Conference. University of California, Davis, pp. 129-133.

Cozza, K., Fico, R., Battistini, M.L., Rogers, E., 1996. The damage-conservation interface illustrated by predation on domestic livestock in central Italy. Biological Conservation 78, 329-336.

Cunningham, S.C., Haynes, L.A., Gustavson, C., Haywood, D.D., 1995. Evaluation of the Interaction Between Mountain Lions and Cattle in the Aravaipa-Klondyke Area of Southeast Arizona. Technical Report no. 17, Phoenix, Arizona Game and Fish Department.

Dar, N.I., Minhas, R.A., Zaman, Q., Linkie, M., 2009. Predicting the patterns, perceptions and causes of human-carnivore conflict in and around Machiara National Park, Pakistan. Biological Conservation 142, 2076-2082.

Ericsson, G., Kindberg, J., Bostedt, G., 2007. Willingness to pay (WTP) for wolverine Gulo gulo conservation. Wildlife Biology 13, 2-12.

Frank, L.G., Woodroffe, R., Ogada, M.O., 2005. People and predators in Laikipia District, Kenya. In: Woodroffe, R., Thirgood, S., Rabinowitz, A. (Eds.), People and Wildlife: Conflict or Coexistence? Cambridge University Press, London, pp. 286304

Fritts, S.H., 1982. Wolf Depredation on Livestock in Minnesota. US Department of the Interior, Fish and Wildlife Service, Resource Publication 145.

Fritts, S.H., Stephenson, R.O., Hayes, R.D., Boitani, L., 2003. Wolves and humans. In: Mech, L.D., Boitani, L. (Eds.), Wolves: Behavior, Ecology, and Conservation. University of Chicago Press, Chicago, pp. 289-316.

Graham, K., Beckerman, A.P., Thirgood, S., 2005. Human-predator-prey conflicts: ecological correlates, prey losses and patterns of management. Biological Conservation 122, 159-171.

Gusset, M., Swarner, M.J., Mponwane, L., Keletile, K., McNutt, J.W., 2009. Humanwildlife conflict in northern Botswana: livestock predation by endangered African wild dog Lycaon pictus and other carnivores. Oryx 43, 67-72.

Holmern, T., Nyahongo, J., Roskaft, E., 2007. Livestock loss caused by predators outside the Serengeti National Park, Tanzania. Biological Conservation 135, 518-526.

Kolowski, J.M., Holekamp, K.E., 2006. Spatial, temporal, and physical characteristics of livestock depredations by large carnivores along a Kenyan reserve border. Biological Conservation 128, 529-541.

Linnell, J.D.C., Smith, M.E., Odden, J., Kaczensky, P., Swenson, J.E., 1996. Strategies for the reduction of carnivore-livestock conflicts: a review. Norwegian Institute for Nature Research Oppdragsmelding 443, 1-118.

Mazzolli, M., Graipel, M.E., Dunstone, N., 2002. Mountain lion depredation in southern Brazil. Biological Conservation 105, 43-51.
McIntyre, R.E., 1995. War Against the Wolf: America's Campaign to Exterminate the Wolf. Voyager Press, Stillwater.

Michalski, F., Boulhosa, R.L.P., Faria, A., Peres, C.A., 2006. Human-wildlife conflicts in a fragmented Amazonian forest landscape: determinants of large felid depredation on livestock. Animal Conservation 9, 179-188.

Muhly, T.B., Musiani, M., 2009. Livestock depredation by wolves and the ranching economy in the Northwestern US. Ecological Economics 68, 2439-2450.

Namgail, T., Fox, J.L., Bhatnagar, Y.V., 2007. Carnivore-caused livestock mortality in Trans-Himalaya. Environmental Management 39, 490-496.

National Agricultural Statistics Service, 2006. Cattle Death Loss, Agricultural Statistics Board, US Department of Agriculture, 19pp. <http:// usda.mannlib.cornell.edu/usda/current/CattDeath/CattDeath-05-05-2006.pdf> (released 05.05.06)

Oakleaf, J.K., Mack, C., Murray, D.L., 2003. Effects of wolves on livestock calf survival and movements in central Idaho. Journal of Wildlife Management 67, 299-306.

Odden, J., Linnell, J.D.C., Moa, P.F., Herfindal, I., Kvam, T., Andersen, R., 2002. Lynx depredation on domestic sheep in Norway. Journal of Wildlife Management 66, 98-105.

Oli, M.K., Taylor, I.R., Rogers, M.E., 1994. Snow leopard Panthera uncia predation of livestock: an assessment of local perceptions in the Annapurna Conservation Area, Nepal. Biological Conservation 68, 63-68.

Palmeira, F.B.L., Craivshaw, P.G., Haddad, C.M., Ferraz, K., Verdad, L.M., 2008. Cattle depredation by puma (Puma concolor) and jaguar (Panthera onca) in centralwestern Brazil. Biological Conservation 141, 118-125.

Parsons, D.R., 1998. "Green fire" returns to the Southwest: reintroduction of the Mexican wolf. Wildlife Society Bulletin 26, 799-807.

Quigley, H.B., Crawshaw, P.G., 1992. A conservation plan for the jaguar Panther onca in the Pantanal region of Brazil. Biological Conservation 61, 149-157.

Reed, J.E., Ballard, W.B., Gipson, P.S., Kelly, B.T., Krausman, P.R., Wallace, M.C., Wester, D.B., 2006. Diets of free-ranging Mexican gray wolves in Arizona and New Mexico. Wildlife Society Bulletin 34, 1127-1133.

Rondinini, C., Boitani, L., 2007. Systematic conservation planning and the cost of tackling conservation conflicts with large carnivores in Italy. Conservation Biology 21, 1455-1462.

Rosas-Rosas, O.C., Bender, L.C., Valdez, R., 2008. Jaguar and puma predation on cattle calves in northeastern Sonora, Mexico. Rangeland Ecology and Management 61, 554-560.

Roy, L.D., Dorrance M.J., 1976. Methods of Investigating Predation of Domestic Livestock: A Manual for Investigating Officers. Alberta Agriculture, Edmonton, Alberta, Canada.

Sagor, J.T., Swenson, J.E., Roskaft, E., 1997. Compatibility of brown bear Ursus arctos and free-ranging sheep in Norway. Biological Conservation 81, 91-95.

SAS, 2003. Version 9.1. SAS Institute, Cary, North Carolina, USA.

Schiess-Meier, M., Ramsauer, S., Gabanapelo, T., Konig, B., 2007. Livestock predation - insights from problem animal control registers in Botswana. Journal of Wildlife Management 71, 1267-1274.

Sommers, A.P., Price, C.C., Urbigkit, C.D., Peterson, E.M., 2010. Quantifying economic impacts of large-carnivore depredation on Bovine Calves. Journal of Wildlife Management 74, 1425-1434.

Stahl, P., Vandel, J.M., Herrenschmidt, V., Migot, P., 2001. The effect of removing lynx in reducing attacks on sheep in the French Jura Mountains. Biological Conservation 101, 15-22.

Swenson, J.E., Andren, H., 2005. A tale of two countries: large carnivore depredation and compensation schemes in Sweden and Norway. In: Woodroffe, R., Thirgood, S., Rabinowitz, A. (Eds.), People and Wildlife: Conflict or Coexistence? Cambridge University Press, London, pp. 323-339.

Treves, A., 2009. Hunting for large carnivore conservation. Journal of Applied Ecology 46, 1350-1356.

United States Fish and Wildlife Service, 2005. Mexican Wolf Blue Range Reintroduction Project 5-year Review. US Fish and Wildlife Service. Albuquerque, New Mexico, USA. <http://www.fws.gov/southwest/es/ mexicanwolf/pdf/MW5YRTechnicalComponent20051231Final.pdf> (retrieved 28.12.09).

Warren, J.T., Mysterud, I., Lynnebakken, T., 2001. Mortality of lambs in free-ranging domestic sheep Ovis aries in northern Norway. Journal of Zoology 254 195-202.

White, G.C., Burnham, K.P., 1999. Program MARK: Survival Estimation from Populations of Marked Animals. Bird Study 46 Supplement, pp. 120-138.

Williams, C.K., Ericsson, G., Heverlein, T.A., 2002. A quantitative summary of attitudes toward wolves and their reintroduction (1972-2000). Wildlife Society Bulletin 30, 575-584.

Woodroffe, R., Thirgood, S., Rabinowitz, A., 2005. The impact of human-wildlife conflict on natural systems. In: Woodroffe, R. Thirgood, S., Rabinowitz, A. (Eds.) People and Wildlife: Conflict or Coexistence? Cambridge University Press, London, pp. 1-12.

Yom-Tov, Y., Ashkenazi, S., Viner, O., 1995. Cattle predation by the golden jackal Canis aureus in the Golan Heights, Israel. Biological Conservation 73, 19-22.

Young, S.P., Goldman, E.A., 1944. The Wolves of North America. Dover Publications, New York.

Zabel, A., Holm-Müller, K., 2008. Conservation performance payments for carnivore conservation in Sweden. Conservation Biology 22, 247-251. 